\title{
Preparation and Characterization of Cr-free passivation films on zinc coating using Response Surface Methodology and Electrochemical Methods
}

\author{
Yuhan Yao, Zhaolin Zhan, Jianxiong Liu, Xiao Wang, Xiaohua Yu*, Ju Rong* \\ Faculty of Materials and Engineering, Kunming University of Science and Technology, Kunming, \\ Yunnan 650093, P. R. China \\ *E-mail: JRong_kmust@163.com (Rong Ju), and xiaohua_y@163.com (Yu Xiaohua)
}

doi: $10.20964 / 2019.09 .07$

Received: 6 May 2019 / Accepted: 24 June 2019 / Published: 31 July 2019

\begin{abstract}
Response surface methodology (RSM) was used in this study to determine the optimum operating conditions for the reduction of galvanized sheet corrosion using a $\mathrm{Cr}$-free passivation films. Passivation films layer with strong corrosion resistance was formed on the surface of galvanizing which was impregnated in chromium-free passivating agent. Furthermore, the RSM was used to ascertain the main and interactive effects (deviation between the experimental and theoretical values: $0.12 \%$ ). The coefficient of determination $\left(\mathrm{R}^{2}\right)$ showed that the RSM approach was appropriate for optimization of the Cr-free passivator. Silane coupling agent, ammonium molybdate, nanosilica, and tannic acid played a key role in changing the corrosion area and potential. The results revealed that, compared with $\mathrm{Cr}^{6+}$ passivation, $\mathrm{Cr}$-free passivation yielded considerably more homogeneous and smoother surfaces (surface roughness of Cr-free passivation film: $0.54 \mu \mathrm{m}$ ). In addition, the properties of the zinc coating after $\mathrm{Cr}-$ free passivation were clearly superior to those of the zinc coating subjected to the conventional $\mathrm{Cr}^{6+}$ passivation treatment. $E_{\text {corr, }}$ current density, and polarization resistance values of this superior coating were $-1073 \mathrm{mV}, 0.017 \mathrm{~A} \mathrm{~cm}^{-2}$, and $989.2 \Omega$, respectively. This study can serve as an experimental and a theoretical guide for the development of Cr-free passivation films.
\end{abstract}

Keywords: Cr-free passivation film; galvanized sheet; electrochemical corrosion

\section{FULL TEXT}

(C) 2019 The Authors. Published by ESG (www.electrochemsci.org). This article is an open access article distributed under the terms and conditions of the Creative Commons Attribution license (http://creativecommons.org/licenses/by/4.0/). 